\title{
The Professional Setting and Adaptability Analysis of Industry Structure of Transportation Higher Vocational Education of Xinjiang under the Background of "The Belt and Road Initiative"
}

\author{
Wei Mao ${ }^{\mathrm{a}}$, Ruhyan Muhmar ${ }^{\mathrm{b}}$, Jie $\mathrm{Li}^{\mathrm{c}}$ and Shefeng Guo \\ Xinjiang Vocational and Technical College of Communications, Urumqi 831401, China \\ amw7397@126.com, ${ }^{b}$ ruheiyan@qq.com, ${ }^{\text {c3389679914@qq.com, }{ }^{d} 595427477 @ q q . c o m}$
}

\begin{abstract}
Keywords: The Belt and Road Initiative; Professional setting; Transportation industry structure; Adaptability analysis
\end{abstract}

\begin{abstract}
In this paper, based on transportation industry structure and employee status in Xinjiang province, and according to the professional setting and employee status of higher vocational education college specializing in transportation (highway, railway and civil aviation inclusive), the transportation industry structure and the professional setting of transportation-related college were analyzed, in order to obtain the strategies about professional setting of higher vocational transportation education in Xinjiang province.
\end{abstract}

\section{Introduction}

According to the survey report on the talent resources statistics of the transportation industry in the autonomous region, the total number of transportation employees in the autonomous region is small, only $3.6 \%$ of the total population of Xinjiang. In particular, the number of high levels of professional and technical personnel, and skilled personnel is much less. As a bridgehead of the "Silk Road Economic Belt", Xinjiang has a large amount of transportation infrastructures. In addition, due to the special environment in Xinjiang, it is difficult to recruit talents, and the professional technicians are scarce, so fewer local colleges and universities set up traffic-related majors, and professional settings are also uneven. Higher vocational education, as a base for cultivating high-quality laborers and skilled personnel directly serving the local economy, should proactively adapt itself to the needs of higher vocational education through strategic readjustment of the industrial structure, optimize professional settings in a timely manner, predict economic trends and demand for talent in advance, and make the setting up of higher vocational education be synchronized with the strategic adjustment of the current industrial structure, so that it can meet the needs of social and economic development and the qualified personnel can be marketable.

There is a certain degree of domestic research on the correlation between a certain industry and its industrial structure[1]. However, studies on the adaptability of industrial settings and industrial structure in Xinjiang mainly carry out corresponding studies on the macro-industrial and economic aspects[2-5]. The total amount of the research results is less, the forms are single, and the research on the specific settings of the transportation specialty and the corresponding adaptability of the industrial structure is almost blank. At present, individual schools in Xinjiang have traffic-related majors, and the overall performance of professional settings is incomplete, specialized and repetitive. Therefore, it is urgent to carry out the setting of comprehensive traffic specialty and the analysis of the cultivation and application of applied talents in the transportation industry in order to meet the demand of talent for the construction of Silk Road Economic Belt.

\section{The Current Situation of Transportation Industry Structure in Xinjiang}

Determining the traffic conditions in a certain area mainly depends on the following indicators: railway mileage, highway mileage, inland waterway mileage, cargo throughput and cargo (passenger) traffic volume. There is no waterway transportation in Xinjiang, so we do not need to consider it. We start with these indicators and objectively present the development of the transportation industry in Xinjiang in the recent five years. 
The Current Situation of Transportation Industry in Xinjiang. In terms of the structure of transportation industry, according to statistics of Xinjiang Statistical Yearbook on the transportation industry, the transportation volume of goods and the turnover of goods completed by various modes of transportation in Xinjiang during the recent 5 years from 2011 to 2015 are shown in Table 1. The proportion of goods transported by various means of transportation can be obtained. The main transportation of goods is highway transportation. It accounts for $88.85 \%$ of the total proportion. The second is the transportation of railway and gas pipeline, which accounts for about $10 \%$ and the volume of civil aviation is very small. In terms of the turnover of the goods, the proportion of the railway and the highway is roughly equal to about $50 \%$. The second is the transportation of oil and gas pipeline, which accounts for $20.6 \%$ and the proportion of civil aviation is as small as the same. From the passenger volume and turnover volume of the main passenger way, we can see that the passenger traffic in Xinjiang is mainly highway transportation, which accounts for $94.7 \%$, and the proportion of railway and civil aviation is relatively small, which is $4.1 \%$ and $1.2 \%$. However, although passenger traffic volume is still in the first place, its proportion is $56 \%$, but the turnover of the railway and civil aviation is not small, which reaches $28.28 \%$ and $15.71 \%$.

Through the comprehensive analysis of Table 1, we can see that in the past five years, from 2011 to 2015, the proportion of goods transported by various transportation modes in Nanjing District of Xinjiang area is: highway: railway: civil aviation $=81.11: 82.03: 0.07$. The proportion of passenger turnover is: highway: railway: civil aviation $=38.79: 19.58: 10.88$. Taking the turnover of goods and passenger turnover as the same weight, we can draw the conclusion that the proportion of industrial structure of the four modes of transportation is: road: railway: civil aviation $=59.95: 50.81: 5.48$ and the proportion of four modes of transport(mean value) can be calculated: highway $52.85 \%$, railway 39.27 , and civil aviation $7.86 \%$.

Table 1. Freight volume and turnover of various modes of transportation in Xinjiang from 2011 to 2015

\begin{tabular}{|c|c|c|c|c|c|c|c|c|}
\hline \multirow{2}{*}{ year } & \multicolumn{3}{|c|}{ Freight volume (ten thousand tons) } & \multicolumn{3}{c|}{ Freight turnover (100 million tons) } \\
\cline { 2 - 9 } & total & railway & highway & $\begin{array}{c}\text { civil } \\
\text { aviation }\end{array}$ & total & railway & highway & $\begin{array}{c}\text { civil } \\
\text { aviation }\end{array}$ \\
\hline 2011 & 70361.9 & 6904 & 55965 & 3.9 & 2199.52 & 857.01 & 852.17 & 0.97 \\
\hline 2012 & 78248.8 & 6933 & 61850 & 5.8 & 2558.68 & 910.58 & 946.9 & 1.44 \\
\hline 2013 & 83716.66 & 7399 & 68528 & 6.66 & 2490.29 & 996.71 & 1055.2 & 1.600 \\
\hline 2014 & 90249.16 & 7529 & 74432 & 7.16 & 2777.28 & 970.46 & 1156.4 & 1.728 \\
\hline 2015 & 80190.6 & 6234 & 64505 & 6.6 & 2605.46 & 819.04 & 1060.46 & 1.660 \\
\hline total & $\mathbf{6 0 8 6 2 8 . 4 4}$ & $\mathbf{6 7 8 1 6}$ & $\mathbf{5 4 0 7 6 4}$ & $\mathbf{4 8 . 4 4}$ & $\mathbf{1 6 3 2 1 . 6 4}$ & $\mathbf{8 2 0 3 . 2 9}$ & $\mathbf{8 1 1 0 . 9 5}$ & $\mathbf{7 . 3 9 8}$ \\
\hline proportion & $\mathbf{1 0 0 \%}$ & $\mathbf{1 1 . 1 4 \%}$ & $\mathbf{8 8 . 8 5 \%}$ & $\mathbf{0 . 0 1 \%}$ & $\mathbf{1 0 0 \%}$ & $\mathbf{5 0 . 2 6 \%}$ & $\mathbf{4 9 . 6 9 \%}$ & $\mathbf{0 . 0 1 \%}$ \\
\hline \multirow{2}{*}{ year } & Passenger volume (ten thousand people) & Passenger turnover $(100$ million km) \\
\cline { 2 - 10 } & total & railway & highway & civil & total & railway & highway & civil \\
\hline 2011 & 50461 & 2002 & 47927 & 532 & 758.26 & 216.16 & 437.90 & 104.16 \\
\hline 2012 & 55298 & 2162 & 52473 & 663 & 849.25 & 236.72 & 478.50 & 134.03 \\
\hline 2013 & 59024 & 2318 & 56000 & 706 & 895.50 & 250.83 & 499.40 & 145.27 \\
\hline 2014 & 55880 & 2355 & 52798 & 727 & 849.80 & 245.60 & 458.70 & 145.50 \\
\hline 2015 & 35824 & 2751 & 32310 & 763 & 645.52 & 252.46 & 241.57 & 151.49 \\
\hline total & $\mathbf{4 6 1 2 5 9}$ & $\mathbf{1 8 9 3 8}$ & $\mathbf{4 3 6 8 3 1}$ & $\mathbf{5 4 9 0}$ & $\mathbf{6 9 2 4 . 7 4}$ & $\mathbf{1 9 5 8 . 0 2}$ & $\mathbf{3 8 7 8 . 7 7}$ & $\mathbf{1 0 8 7 . 9 1}$ \\
\hline proportion & $\mathbf{1 0 0 \%}$ & $\mathbf{4 . 1 \%}$ & $\mathbf{9 4 . 7 \%}$ & $\mathbf{1 . 2 \%}$ & $\mathbf{1 0 0 \%}$ & $\mathbf{2 8 . 2 8 \%}$ & $\mathbf{5 6 . 0 1 \%}$ & $\mathbf{1 5 . 7 1 \%}$ \\
\hline
\end{tabular}

Personnel Structure in Transportation Industry. Through the statistics from 2011 to 2015 in Xinjiang, the transportation industry practitioners showed that the average number of road transport industry practitioners in recent five years was about 62 thousand people, the railway transportation 
was about 49 thousand and 500 people, the air transportation was about 12 thousand people, the pipeline transportation was about 4 thousand people, handling and transportation agent industry was about 5 thousand people, the storage industry was about 3 thousand people, and the postal industry was about 13 thousand people. Thus we can launch the proportion of employees from 2011 to 2015 in Xinjiang during the transportation industry: road transportation: railway transportation: air transportation: pipeline transportation: handling and transportation agency: warehousing: post industry: $=42.06: 33.34: 7.86: 2.86: 3.22: 2.10: 8.56$. The change trend of the number of employees in Xinjiang transportation industry from 2011 to 2015 is shown in Fig.1.

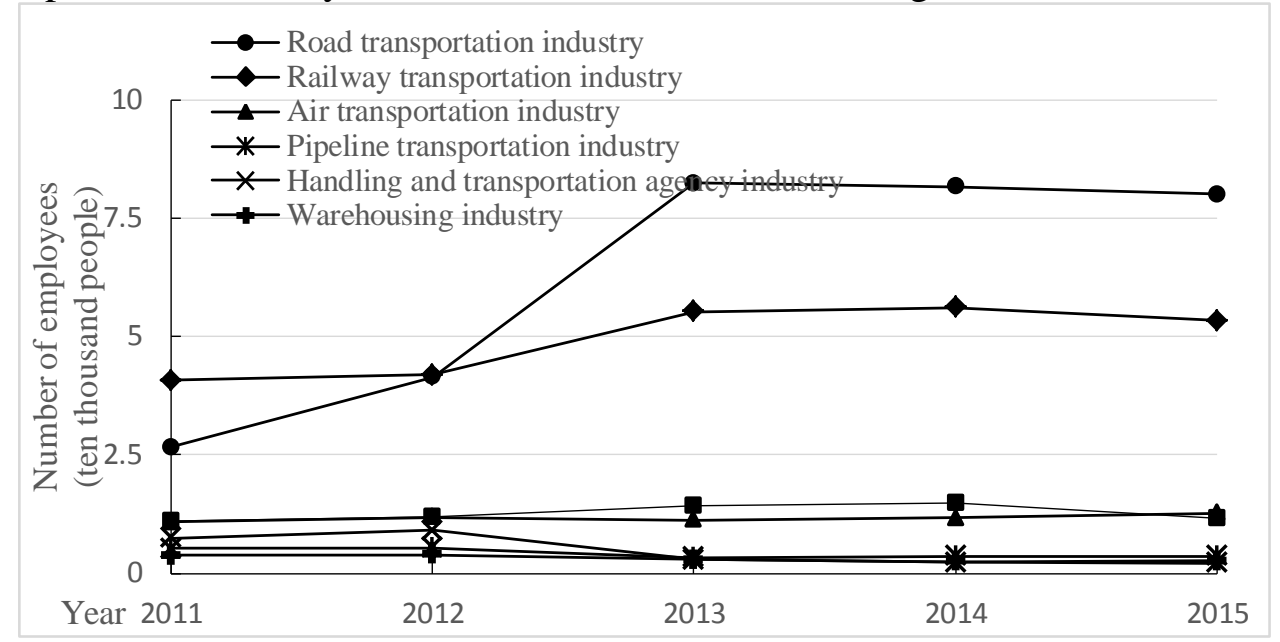

Figure 1. The change trend of the number of employees in Xinjiang transportation industry from 2011 to 2015

\section{The Professional Setting and Employment Status of Xinjiang Transportation Vocational Colleges}

By the end of 2016, there were 27 vocational colleges in Xinjiang. There were 16 colleges related to transportation. Only two of them are completely traffic colleges and the remaining 14 colleges have an average of 1-3 majors in related majors. Therefore, this statistical analysis focuses on two vocational colleges for traffic transportation. There are 45 majors in these two colleges. According to the statistics, a total of 38 traffic majors such as road bridges, delivery vehicles, rail transit, traffic and logistics, account for $84.4 \%$ of the total, six majors which are related to traffic and transportation of computers and machinery account for $13.3 \%$ of the total, and there is one non-traffic major, which accounts for $2.2 \%$ of the total. Statistics calculated that their proportion is: highway: railway: civil aviation $=48.89: 37.78: 0$.

Based on the statistics of employment data in recent 5 years in transportation colleges, the total number of training students is about 10 thousand and 800, the average employment rate is $78.7 \%$, and the average employment rate in transportation industry is $61.25 \%$. According to the statistics on employment situation, there are $68.04 \%$ of the employed persons, $25.17 \%$ of vehicle carriers, $0.6 \%$ of rail transit, $1.5 \%$ of railways and $4.68 \%$ of transportation and logistics, which are engaged in traffic related professional fields. Among non traffic related majors, $45.41 \%$ are mechanical and electrical machinery, $38.32 \%$ are computers, and others account for $16.25 \%$. Therefore, it is possible to approximate the proportion of the number of graduates corresponding to three industrial categories from 2011 to 2015: highway: railway: civil aviation $=53.24: 1.2: 0$.

\section{Adaptability Analysis of Xinjiang Traffic Industry Structure and Traffic Professional Setting}

Professional Structure Adaptability Analysis. According to the comparative analysis of the professional structure and transportation industry structure of the two transportation colleges, it is found that the professional structure of the highway is $3.96 \%$ less than that of the industrial structure, and the professional structure of the railway is $1.49 \%$ less than that of the industrial 
structure. The professional structure of civil aviation is $7.86 \%$ less than that of the industrial structure. It can be seen from this that the two transport-based institutions are able to meet the road-based transportation industry pattern in Xinjiang based on their professional structure. However, there are large differences in the proportions of the professional structures of roads, railways and civil aviation with the industrial structure, especially the civil aviation. There are basically no specialties in civil aviation in the two transportation vocational colleges in Xinjiang. With the rapid construction and continuous improvement of the comprehensive transportation system of the "Silk Road Economic Belt" in Xinjiang, the civil aviation industry will enjoy rapid development. We can formulate relevant policies to increase the construction of civil aviation professional groups in vocational colleges in Xinjiang.

Adaptability Analysis of the Structure of Personnel Training and the Structure of Employees. According to the statistical indicators of the Statistical Yearbook, the structure of the transportation industry practitioners is divided into road transportation, railway transportation, air transportation, pipeline transportation, handling and transportation agency, warehousing and post industry. Therefore, we compare and analyze the personnel training structure of vocational colleges in transportation from these fields. According to the statistics, the proportion of graduates corresponding to different employment directions of two transport colleges in Xinjiang from 2011 to 2015 is: 53.24: 1.2: 0: 0: 0: 2.67: 0. Compared with the transportation industry structure (Table 2), it is found that the road transportation has trained $11.18 \%$ more than the employees and $0.57 \%$ more than the warehousing logistics. In other industries there is a serious shortage of personnel training structure and professional structure.

Table 2. Comparison of personnel training structure and personnel structure in transportation industry

\begin{tabular}{|c|c|c|c|c|c|c|c|}
\hline & $\begin{array}{c}\text { Road } \\
\text { transport } \\
\text { industry }\end{array}$ & $\begin{array}{c}\text { Railway } \\
\text { transport } \\
\text { industry }\end{array}$ & $\begin{array}{c}\text { Air } \\
\text { transport } \\
\text { industry }\end{array}$ & $\begin{array}{c}\text { Pipeline } \\
\text { transporta } \\
\text { tion }\end{array}$ & $\begin{array}{c}\text { Handling and } \\
\text { transport } \\
\text { agents }\end{array}$ & $\begin{array}{c}\text { Wareho } \\
\text { using }\end{array}$ & $\begin{array}{c}\text { Post } \\
\text { industr } \\
\mathrm{y}\end{array}$ \\
\hline $\begin{array}{c}\text { Structure of } \\
\text { personnel } \\
\text { training (\%) }\end{array}$ & 53.24 & 1.2 & 0 & 0 & 0 & 2.67 & 0 \\
\hline $\begin{array}{c}\text { Structure of } \\
\text { employees (\%) }\end{array}$ & 42.06 & 33.34 & 7.86 & 2.86 & 3.22 & 2.10 & 8.56 \\
\hline Difference & 11.18 & -32.14 & -7.86 & -2.86 & -3.22 & 0.57 & -8.56 \\
\hline
\end{tabular}

In general, during the past five years, two vocational colleges in Xinjiang have paid attention to training technical personnel for highway transportation. The major categories established basically cover the main occupations required for road traffic construction. Roads, bridges, vehicles, transportation and logistics play a leading role in professional settings, and form the brand and characteristics of transportation vocational education. However, with the construction of the "One Belt and One Road" bridgehead in Xinjiang and the great development of transport infrastructure in Xinjiang, there is a great demand for professionals in such industries as railways, aviation and postal logistics, and the professional settings need to be further strengthened.

\section{Suggestions on the Professional Setting of Xinjiang Transportation Higher Vocational Education}

Highlighting the Characteristics of the Transportation Industry. The nature of the application of skilled personnel training in higher vocational education determines that the relationship between the industry and the education sectors are inseparable. Xinjiang Vocational and Technical College of Transportation has set foot in big traffic, facing Xinjiang and radiating Central Asia in professional setting, and has distinctive industry characteristics. With the goal of one trillion Yuan investment in transportation construction industry during the "13th Five-Year Plan" in Xinjiang, the adjustment of transportation industrial structure will put forward new demands on the development of comprehensive transportation structure, Silk Road channel structure and road network structure. 
Structural arrangement and optimization should pay close attention to the new trend of national and regional transport industry development, pay attention to the adjustment and adaptability of existing transport professionals, and always reflect the characteristics of integrated transport industry as the core concept of its professional structure optimization.

At the same time, transport agencies should strengthen relying on transportation industry. The transportation industry should constantly improve and deepen cooperation in the area of all kinds of transportation enterprises, give full play to achieve building major under the support of the structure of professional cooperation and optimization plan, timely adjust the direction of development of the transportation industry, improve the sensitivity of the target culture the professional services industry and reduce the construction cost of professional personnel. At the same time, the integration of resources should be based on the building of " $4+0$ " and " $3+2$ " undergraduate departments and "professional groups" in higher vocational education in transportation and give full play to the functions of jurisdiction, integration, and highlight the characteristics of professional brands, so as to build a transport-oriented professional, related professionals and other professional mutual support and coordinated development of integrated transport ecosystem.

Transport Industry Enterprises Should Change Their Concepts and Enhance Their Long-Term Awareness. With the continuous promotion of the "Silk Road Economic Belt," Xinjiang will invest 200 billion yuan in transport construction in 2017 and over 1 trillion yuan in transport construction in the "13th Five-Year Plan", and will fully implement the strategy of "strengthening cooperation through science and technology" and " strengthen hand in hand " to promote the deep integration of transportation, production and research. This requires a large number of traffic applications of technical personnel. At present, local vocational colleges in Xinjiang cannot meet the demand of enterprises, and most of the students recruited from the mainland cannot take root in Xinjiang for a long time. It causes the enterprise to train employees to appear out of the generation, so that the Xinjiang transportation industry is seriously lack of professional technical personnel. The professional skilled labor is the fundamental factor to promote the optimization and upgrading of industrial structure and the development of enterprises. In order to obtain good economic benefits and improve market competitiveness, the transport enterprises in Xinjiang under special geo-environment must establish a long-term and stable cooperative relationship with local vocational colleges. In the process of interactive development with vocational colleges in the industry, we should not only be keen on the immediate benefits of "short and flat and fast", but also should insist on long-term interests and enhance our professional technical development and personnel training by relying on awareness, care and support in local vocational colleges. If we combine the long-term development goals of enterprises with the development prospects of vocational education, we can transform the advantages of skilled talents in local vocational colleges into the technological strength and talent strength of enterprises, so as to enhance their own competitiveness and achieve the goal of sustainable development.

Professional Colleges Should Keep Pace with the Times. Setting or adjusting the professional colleges and universities will usually meet the requirements of the adjustment of industrial structure in the region, actively adjust the professional structure and personnel training scale, and set reasonable professional needs of the market to adapt and promote Silk Road bridgehead construction in Xinjiang. At present, most of the orbital construction and operation management talents in Xinjiang are trained mainly through the orientation of universities and colleges in the mainland. Only a small part of local colleges and universities have been trained. In addition, neither civil aviation service nor high-speed railway service professionals have been set up. According to the above analysis data, under the background of the construction of an integrated transportation network such as the Xinjiang expressway network, the high-speed railway network and the aviation hub, the proportion of the professional internal scale of the highway industry should be gradually and reasonably optimized. Relevant professions of high-speed railway and orbital engineering construction and operation management service should be increased. And at the same time, it is necessary to properly control the enrollment scale of related professional carriers for road transport vehicles, reduce unnecessary waste of resources and relative surplus personnel, and strengthen the 
construction of post-operation maintenance specialty in the later period of highway construction.

\section{Acknowledgements}

Fund project: The youth project of the Ministry of Education of the National Education Science "12th Five-Year" Planning "The Adaptability Analysis of Professional Setting of Transportation-Related Higher Vocational College and the Transportation Industry Structure in Xinjiang under the Background of "The Belt and Road"” project(Number:EJA150382).

\section{References}

[1] J.Wang: Analysis of the Professional Setting of Nanjing Transportation Vocational College and Structural adaptability of traffic industry in Nanjing, (MS., Nanjing Normal University, China 2012).(In Chinese).

[2] M.Zhang: Analysis of the Demand for the Evolution of Employment Structure in Xinjiang on Vocational Education, Academy, Vol.31 (2015), p.113-114.(In Chinese).

[3] D.M.Wang, X.M.Xiang and L.Xu: An Analysis of the Interaction between Vocational Education and Industrial Structure in Xinjiang, Economic and Social Development, Vol. 11 (2013) No.1, p.48-50.(In Chinese).

[4] D.M.Wang: Analysis on the Demand of Industrial Structure evolution to Vocational Education in Xinjiang[J], Northern Economy, Vol.14 (2012), p.51-52.(In Chinese).

[5] X.W.Sun and J.S.Wang: Analysis on the Adaptability of Professional Setting and Regional Economic Development in Xinjiang Higher Vocational Colleges, Higher Vocational Education(Journal of Tianjin Vocational Institute), Vol.20 (2011) No.03, p.18-21.(In Chinese). 